\title{
Fracture Behavior of Amorphous and Semicrystalline Blends of Poly(vinylidene fluoride) and Poly(methyl methacrylate)
}

\author{
Lucien Laiarinandrasana, ${ }^{1}$ Yannick Nziakou, ${ }^{2}$ Jean Louis Halary ${ }^{2}$ \\ ${ }^{1}$ MINES ParisTech, Centre des Mat'eriaux - CNRS UMR 7633, BP 87, 91003 Evry, Cedex, France \\ ${ }^{2}$ ESPCI ParisTech, SIMM Lab. - UPMC/CNRS/ESPCI UMR 7615, 10 rue Vauquelin, 75231 Paris, Cedex 05, France \\ Correspondence to: L. Laiarinandrasana (E-mail: lucien.laiarinandrasana@mines-paristech.fr)
}

\begin{abstract}
The fracture behavior of blends of poly(vinylidene fluoride) and poly(methyl methacrylate) was investigated all over the composition range. A detailed analysis of the net stress versus crack opening displacement curves was performed. Fracture surface observations allowed statements on the process zone characteristics ahead of the crack tip. For the amorphous blends, the crack initiation energy is well related to the glass transition
\end{abstract}

INTRODUCTION After extensive studies starting in the 1970s in relation to miscibility and piezoelectric properties, ${ }^{1-6}$ the blends of poly(vinylidene fluoride) (PVDF) and poly(methyl methacrylate) (PMMA) got a renewal of interest in recent years with studies aiming at assessing their mechanical behavior. $^{7-9}$ By increasing the PVDF content, these blends present a transition from amorphous to semicrystalline structure, which is likely to affect most mechanical properties. Right now, emphasis has been put on the stress-strain behavior of the blends in tension and compression ${ }^{7,8}$ over the low deformation range covering the elastic, anelastic, and viscoplastic response and molecular interpretations have been proposed. ${ }^{9}$ The aim of the present communication is to complement this analysis with the characterization of some failure properties, including toughness, in connection to blend relaxation and crystallization features.

\section{EXPERIMENTAL}

\section{Materials and Blending Conditions}

The PVDF/PMMA blends were prepared from the homopolymers PVDF Kynar ${ }^{\circledR} 721$ and PMMA Oroglas ${ }^{\circledR}$ V825, both kindly provided by the company Arkema France. Blending was achieved by co-precipitation from a homogeneous solution. For this purpose, a dilute solution was prepared by dissolving 5 wt $\%$ of the two polymeric materials in dimethylformamide, under a continuous stirring at $50{ }^{\circ} \mathrm{C}$. To ensure a complete dissolution, stirring duration was as long as $48 \mathrm{~h}$ for the amorphous blends and $72 \mathrm{~h}$ for the semicrystalline ones. Then, PVDF and PMMA were co-precipitated by pouring the solution drop by drop into a large excess of temperature. For the semicrystalline blends, the fracture energy is correlated with the degree of crystallinity.

KEYWORDS: blends; crack initiation; crack propagation; fracture; fracture toughness; mechanical properties; poly(methyl methacrylate); poly(vinylidene fluoride)

water. Finally, the polymeric powder was dried at $100{ }^{\circ} \mathrm{C}$ for about $6 \mathrm{~h}$ in a vacuum oven. The blends were then compression-molded in the form of 5-mm thick sheets. Molding was carried out at $200{ }^{\circ} \mathrm{C}$ under 100 bars for $45 \mathrm{~min}$ and followed by a slow cooling down below the glass transition. For the semicrystalline blends, further annealing was carried out at $150{ }^{\circ} \mathrm{C}$ (an intermediate temperature between the glass transition and melting temperatures) for $60 \mathrm{~h}$ to stabilize the sample to its maximum degree of crystallinity, $\chi$. Samples of the geometry required by the various mechanical tests were machined out of the sheet. Blend identification is based on weight composition. For instance, $\% F=20$ or $F / M$ 20:80 identifies a blend containing 20 wt $\%$ of PVDF and 80 wt $\%$ of PMMA.

\section{Blend Main Characteristics}

As detailed elsewhere, ${ }^{7,9}$ either amorphous or semicrystalline blends are produced, depending on the fraction of PVDF. Typically, the blends remain amorphous when their PVDF content is less than about $50 \mathrm{wt} \%$. Blend composition influences the values of the glass transition temperature, and presence of amorphous PVDF segments constrained by the crystallites has been evidenced in the most crystalline blends. Using data taken from ref. 9, Table 1 recalls the main characteristics of the blends under study, namely overall weight percentage of PVDF, $\% F$, glass transition temperature, $T_{\mathrm{g}}^{\mathrm{FM}}$, degree of crystallinity, $\chi$ and PVDF wt fraction in the amorphous phase, $W^{\mathrm{F}}$ a defined as follows:

$$
W_{\mathrm{a}}^{\mathrm{F}}=(\% \mathrm{~F}-\chi) /(100-\chi)
$$


TABLE 1 Sample Characteristics

\begin{tabular}{lllll}
\hline Sample & $\% F$ & $T_{\mathrm{g}}{ }^{\mathrm{FM}}\left({ }^{\circ} \mathrm{C}\right)$ & $\chi(\%)$ & $W_{\mathrm{a}}^{\mathrm{F}}$ \\
M & 0 & 110 & 0 & 0 \\
F/M 20:80 & 20 & 85 & 0 & 0.20 \\
F/M 30:70 & 30 & 77 & 0 & 0.30 \\
F/M 40:60 & 40 & 58 & 0 & 0.40 \\
F/M 50:50 & 50 & 66 & 14 & 0.419 \\
F/M 60:40 & 60 & 54 & 19 & 0.506 \\
F/M 70:30 & 70 & 45 & 27 & 0.589 \\
F/M 80:20 & 80 & 54 & 36 & 0.688 \\
F/M 90:10 & 90 & 53 & 45 & 0.818 \\
F & 100 & -40 & 55 & 1
\end{tabular}

The data are taken from ref. 9.

\section{Fracture Energy Measurements}

The determination of the toughness was performed on single edge notch bending (SENB) specimens for which characteristic dimensions were kept constant: thickness $T=5 \mathrm{~mm}$, width $W=12 \mathrm{~mm}$, crack depth $a=5 \mathrm{~mm}$ (thus $a / W=$ 0.42 ), length $L=70 \mathrm{~mm}$, and span $S=50 \mathrm{~mm}$. The precrack was machined with a notch root radius of $\sim 250 \mu \mathrm{m}$. Tests were carried out on an Inströn testing machine with a constant crosshead speed of $0.5 \mathrm{mms}^{-1}$ for all tests. For the sake of reproducibility, all tests were repeated twice. The load $F$, the notch opening displacement $\delta$ and the crosshead displacement were recorded as a function of the running time. The recording frequency was fixed at $100 \mathrm{~Hz}$. The net stress $\left(\sigma_{\text {net }}\right)$ is defined as the load $F$ divided by the area of the initial net section.

Following fracture mechanics theory, ${ }^{10}$ the energy release rate $G$ can be expressed as:

$$
\mathrm{G}=f(\mathrm{a} / \mathrm{W}) \mathrm{U}
$$

where $f(a / W)$ is a function of the crack depth ratio and the specimen geometry and $U$ the area under the load versus $\delta$ plot. Here both $a / W$ and specimen geometry are kept constant so $G$ is proportional to the area under $\sigma_{\text {net }}$ versus $\delta$. This quantity is homogeneous to an energy density. In the following, this area will be integrated and split into two energies: $E_{\mathrm{i}}$ during the loading path up to the maximum $\sigma_{\text {net }}$ and $E_{\mathrm{p}}$ corresponding to the consecutive decrease in $\sigma_{\text {net }}$. For brittle fracture $E_{\mathrm{p}}=0, E_{\mathrm{i}}$ is therefore related to the critical energy release rate and is representative of the toughness of the material. For the general case where $E_{\mathrm{p}} \neq 0$, the total fracture energy $E_{\mathrm{t}}=E_{\mathrm{i}}+E_{\mathrm{p}}$ can be linked to the impact fracture strength ${ }^{11-13}$ but adapted here to quasistatic loading of the specimen. Both $E_{\mathrm{i}}$ and $E_{\mathrm{t}}$ will then be considered to follow the toughness improvement according to the PVDF content.

\section{Microscopic Examinations}

In the present work, an attempt is made to relating the aforementioned characteristic mechanical parameters to the fracture micromechanisms by examining fracture surfaces of broken specimens. To this end, one fracture surface corresponding to each blend was selected to be inspected with the help of scanning electron microscope (SEM). Prior to microscopic observations, $\mathrm{Au}-\mathrm{Pd}$ coating was applied to the fracture surfaces. The process zone (PZ) where the fracture initiates is first identified. Characteristic lengths such as PZ width, PZ maximum depth and dimple mean diameter within this PZ, are measured. An attempt was then made to correlate them to both the degree of crystallinity of the blend as well as the fracture parameters described above.

\section{RESULTS AND DISCUSSION}

\section{Mechanical Parameters}

\section{Curves of Net Stress Versus $\delta$}

For each test, the main graph used is the net stress $\left(\sigma_{\text {net }}\right)$ as a function of notch opening displacement (noted $\delta$ ). Figure 1 corresponding to $\% F=50$, illustrates the typical trend of this kind of curve. Two stages can be distinguished:

- the loading stage (up to maximum net stress), where the crack is supposed to be stationary at the initial value of a/ $\mathrm{W}=0.42$. This part is concerned with "crack initiation" process and therefore to $E_{\mathrm{i}}$;

- and the crack growth stage, characterized by the decrease of net stress, related then to $E_{\mathrm{p}}$. Although the crack growth rates are high, thanks to the recording frequency of 100 $\mathrm{Hz}$, some experimental points during this stage were recorded. However, more scatter was observed in the propagation stage data.

The main characteristic mechanical parameters, obtained from experimental curves are defined in Figure 1. Their mean values are gathered in Table 2 . In the following, these parameters are plotted as a function of the PVDF content, $\% F$.

\section{Maximum Net Stress, Opening Displacements}

First, the maximum values of the net stress $\left(\sigma_{\text {net }}^{\max }\right)$ are plotted against $\% F$ in Figure 2(a). The curve exhibits four characteristic trends. An increase in $\sigma_{\text {net }}^{\max }$ is first observed from $\% F=0$ to $\% F=30$, followed by a decrease between $\% F=$ 40 and $\% F=60$. A continuous increase in $\sigma_{\text {net }}^{\text {max }}$ is then

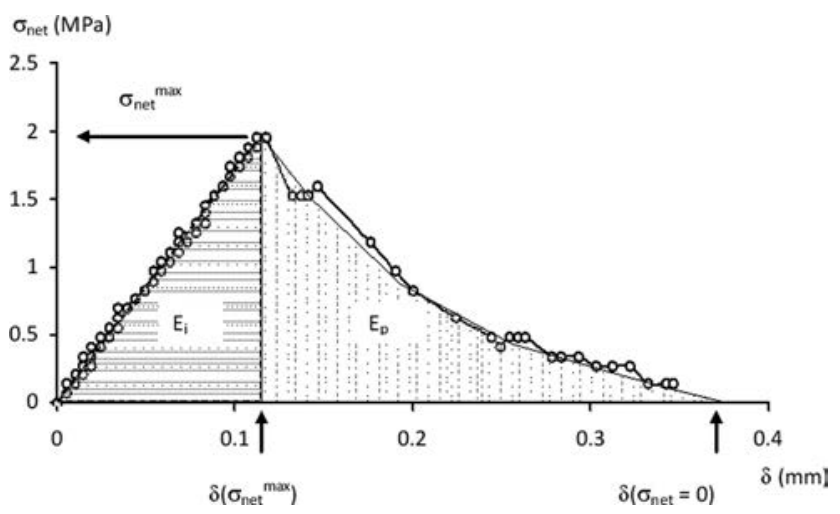

FIGURE 1 Typical net stress versus opening displacement curve for $\% F=50$. Definitions of mechanical parameters: $\sigma_{\text {net }}{ }^{\max }, \delta\left(\sigma_{\mathrm{net}}{ }^{\max }\right), \delta\left(\sigma_{\mathrm{net}}=0\right), E_{\mathrm{i}}$, and $E_{\mathrm{p}}$. 
TABLE 2 Fracture Tests Results

\begin{tabular}{lllllll}
\hline Sample & $\sigma_{\text {net }}^{\max }(\mathrm{MPa})$ & $\delta\left(\sigma_{\text {net }}^{\max }\right)(\mathrm{mm})$ & $\delta\left(\sigma_{\text {net }}=0\right)(\mathrm{mm})$ & $E_{\mathrm{i}}\left(\mathrm{kJ} / \mathrm{m}^{2}\right)$ & $E_{\mathrm{p}}\left(\mathrm{kJ} / \mathrm{m}^{2}\right)$ & $E_{\mathrm{t}}\left(\mathrm{kJ} / \mathrm{m}^{2}\right)$ \\
M & 2.4 & 0.09 & 0.26 & 0.12 & 0.11 & 0.23 \\
F/M 20:80 & 2.7 & 0.12 & 0.27 & 0.19 & 0.22 & 0.41 \\
F/M 30:70 & 2.6 & 0.15 & 0.32 & 0.18 & 0.33 & 0.20 \\
F/M 40:60 & 2.4 & 0.14 & 0.38 & 0.08 & 0.14 & 0.38 \\
F/M 50:50 & 1.8 & 0.11 & 0.38 & 0.05 & 0.08 & 0.22 \\
F/M 60:40 & 1.5 & 0.08 & 0.18 & 0.08 & 5.21 & 0.13 \\
F/M 70:30 & 1.8 & 0.09 & 4.63 & 0.14 & 6.48 & 5.29 \\
F/M 80:20 & 2.4 & 0.12 & 6.89 & 1.19 & 11.29 & 6.62 \\
F/M 90:10 & 5.2 & 0.45 & 6.77 & 3.42 & 25.43 & 12.48
\end{tabular}

observed when $\% F$ is larger than 60 , slightly between 60 and 80 and significantly for the two last $\% F$. Excellent reproducibility of $\left(\sigma_{\text {net }}^{\max }\right)$ values can be noticed in Figure 2(a).

Figure 2(b) displays the crack opening displacements $\delta$ corresponding to respectively, $\sigma_{\text {net }}{ }^{\max }$ (first $y$-axis) and $\sigma_{\text {net }}=0$ at the complete failure of the specimens (second $y$-axis). The same trend as in Figure 2(a) is observed for $\delta\left(\sigma_{\text {net }}^{\max }\right)$ This similarity indicates that during the loading step, the net stress versus $\delta$ curve is quasilinear.

Instead, the evolution of $\delta\left(\sigma_{\text {net }}=0\right)$ versus $\% F$ [Fig. 2(b), second $y$-axis] differs at PVDF content larger than $\% F=60$. Indeed, a jump of this parameter is observed between $\% F=$ 60 and $\% F=80$ whereas the increase of $\delta\left(\sigma_{\text {net }}{ }^{\max }\right)$ is not so significant. In fact, the jump is due essentially to the propagation stage. This can be attributed to additional deformation of the crack tip (blunting) during the propagation. For $\% F \geq 80$ a saturation of $\delta\left(\sigma_{\text {net }}=0\right)$ value is observed.

Attention was paid on the decrease of both $\sigma_{\text {net }}$ max and $\delta\left(\sigma_{\text {net }}^{\max }\right)$ between 40 and $60 \%$. Similar observations have already be done while considering the composition dependence of both yield stress and Young's modulus. ${ }^{9}$ They have been tentatively attributed to experimental difficulties accompanying polymer blending and blend processing.

\section{Fracture Energies $E_{i}, E_{p}, E_{t}$}

Following Laiarinandrasana et al., ${ }^{14}$ both $E_{\mathrm{i}}$ and $E_{\mathrm{p}}$ were numerically integrated by using the experimental data. As mentioned above, they are expressed in $\mathrm{kJ} / \mathrm{m}^{2}$ unit.

Figure 3 displays the fracture energies $E_{\mathrm{i}}$ and $E_{\mathrm{t}}$ in a semilogarithmic scale versus PVDF content. For $E_{\mathrm{i}}$, the trend is the same as that of $\sigma_{\text {net }}{ }^{\max }$ and $\delta\left(\sigma_{\text {net }}^{\max }\right)$, whereas the jump of $E_{\mathrm{t}}$ between $\% F=60$ and $\% F=80$ coincides to that of $\delta\left(\sigma_{\text {net }}=0\right)$. Furthermore, Figure 3 shows that at low values of fracture energy $(0<\% F<60), E_{\mathrm{t}} \approx 2 E_{\mathrm{i}}$. This is due to that $E_{\mathrm{i}}$ and $E_{\mathrm{p}}$ have approximately the same value. In the upper shelf of the fracture energy $(\% F>70) E_{\mathrm{p}}$ is of higher order of magnitude than $E_{\mathrm{i}}$.

The effects of the PVDF content on the toughness are observed when $\% F>60$ on both $E_{\mathrm{i}}$ and $E_{\mathrm{t}}$. However, depending on the selected fracture parameter, the observed gain in toughness may significantly differ in their absolute value (Factor 10).

At this stage, the sensitivity of mechanical parameters according to PVDF contents can be analyzed with the help of $E_{\mathrm{i}}$ and $E_{\mathrm{p}}$ parameters.

$$
\sigma_{\text {net }}^{\max }(\mathrm{MPa})
$$
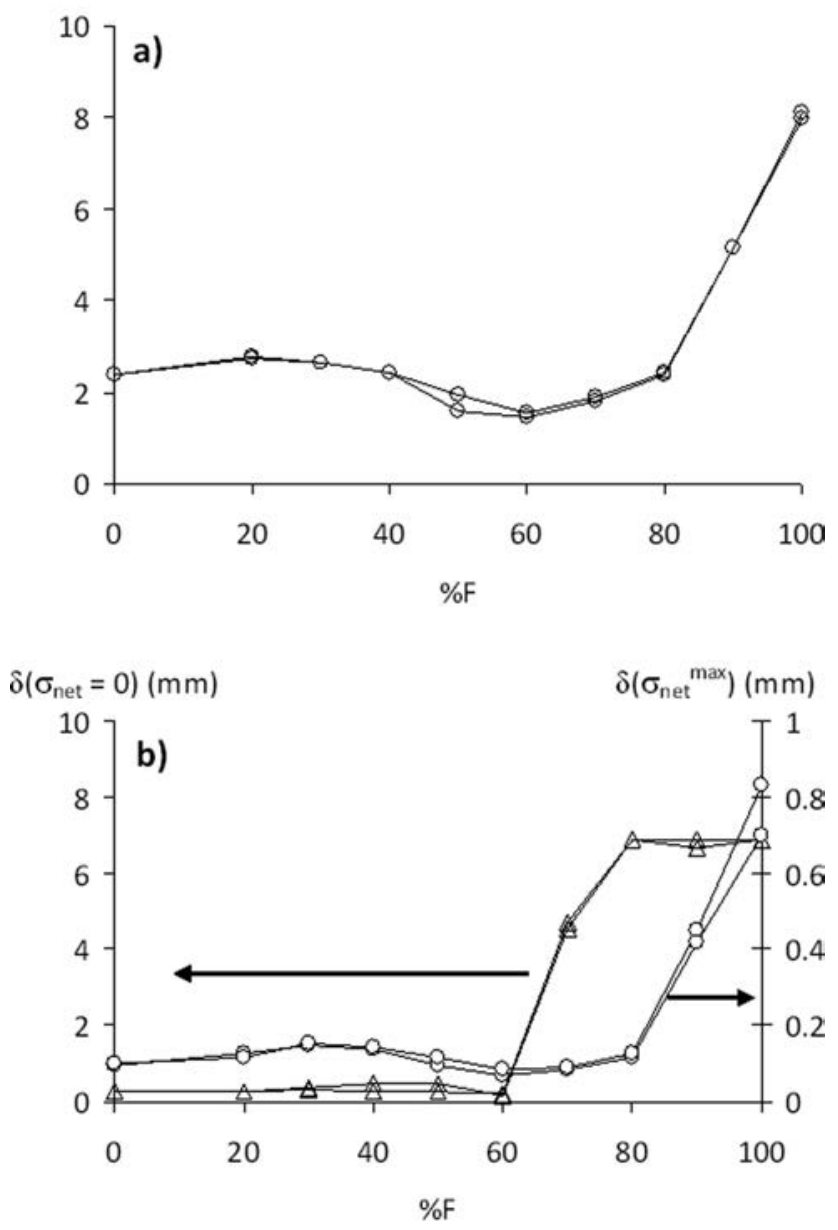

FIGURE 2 Mechanical parameters plotted against PVDF contents $(\% F)$ : (a) $\sigma_{\text {net }}^{\text {max; }}$; (b) $\delta\left(\sigma_{\text {net }}^{\max }\right)$, empty circles and $\delta\left(\sigma_{\text {net }}=\right.$ $0)$, empty triangles. 


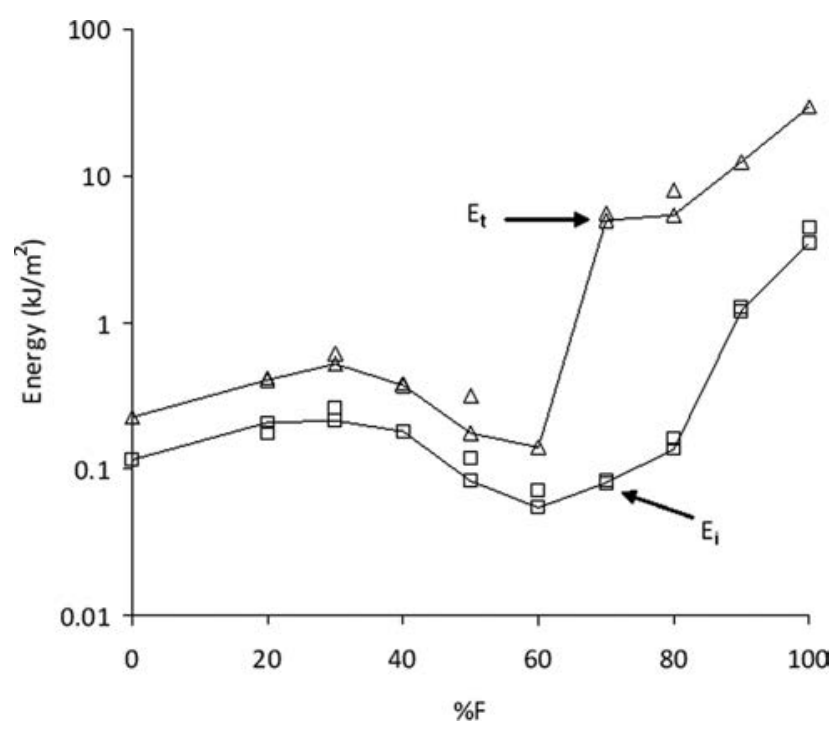

FIGURE 3 Fracture energies plotted as a function of PVDF contents $\left(E_{\mathrm{i}}\right.$; empty square; $E_{\mathrm{t}}$ : empty triangle).

- $0 \leq \% \mathrm{~F} \leq 40$, this domain is concerned with amorphous blends. A neat increase of both fracture energies is noticed up to $\% \mathrm{~F}=30$ followed by a slight decrease at $\% \mathrm{~F}=40$. At this latter PVDF content, although the blend was still amorphous, it can be supposed that the slight decrease in $E_{\mathrm{i}}$ and $E_{\mathrm{t}}$ is due to the effect of the crystallinity in the next stage. Minimum fracture energy value is that of PMMA and the maximum increase is observed at $\% \mathrm{~F}=30$ (Factor 2) for amorphous blends;

- $40 \leq \% F \leq 60, E_{\mathrm{i}}$ and $E_{\mathrm{p}}$ decrease when $\% F$ increases. This concerns the first part of the semicrystalline domain. Small values of the fracture energy are observed. Theoretically, this corresponds to the brittle fracture domain for the semicrystalline blend. Therefore, the decrease in the fracture energies in this domain is likely due to that: the maximum fracture energies of the amorphous blend (for $\% F=30 ; E_{\mathrm{i}}=0.23 \mathrm{~kJ} / \mathrm{m}^{2}, E_{\mathrm{t}}=0.56 \mathrm{~kJ} / \mathrm{m}^{2}$ ) are higher than the minimum fracture energies of the semicrystalline blend (for $\% F=60 ; E_{\mathrm{i}}=0.05 \mathrm{~kJ} / \mathrm{m}^{2}, E_{\mathrm{t}}=0.13 \mathrm{~kJ} / \mathrm{m}^{2}$ );

- $60 \leq \% F \leq 70$, a strong increase $E_{\mathrm{t}}$ is observed. This jump is noticeable only for the total energy of fracture, although an increase of $E_{\mathrm{i}}$ is also observed. The shape of $E_{\mathrm{t}}$ versus $\% F$ suggests that the brittle to ductile transition PVDF content is around $\% F=65$. However, this is not valid for $E_{\mathrm{i}}$;

- $70 \leq \% F \leq 100$, a regular increase of the fracture energies is observed as a function of $\% F$. The maximum values of fracture energy are that of the PVDF homopolymer ${ }^{15-17}$ and in this last domain the blend fracture properties can be controlled by the PVDF content.

\section{Fractography}

Fracture surface analysis was systematically performed after each test. The motivation here is to find out what the fracture surface observations can help to better understand the abovementioned partition related to the PVDF contents
$(\% F)$. The main trends are summarized in Figures 4-6. Although not presented in these figures, a large part of the surface corresponding to the crack propagation is rather flat, like brittle fracture surface. However, it was clearly observed that the higher the degree of crystallinity, the more the rugosity of the crack growth fracture surface. The following discussion is then based on the PZ ahead of the crack tip, prior to the crack growth surface, keeping in mind that fracture surfaces of amorphous and semicrystalline polymers are quite different. Moreover, the $\mathrm{PZ}$ corresponds to the crack initiation stage and accordingly, related to $E_{\mathrm{i}}$.

Figure 4 dedicated to $0 \leq \% F \leq 40$ is illustrative of the fracture surface of $\% F=20$ blend but the observations are representative of the other samples issued from $\% F \leq 40$. Figure 4(a) shows the aspect of fracture surface at a macroscopic scale. The direction of crack propagation is represented by the white arrow. The examination is based on the area below the line of initial crack front. Dashed line indicates the contour of the $\mathrm{PZ}$ that has been identified by

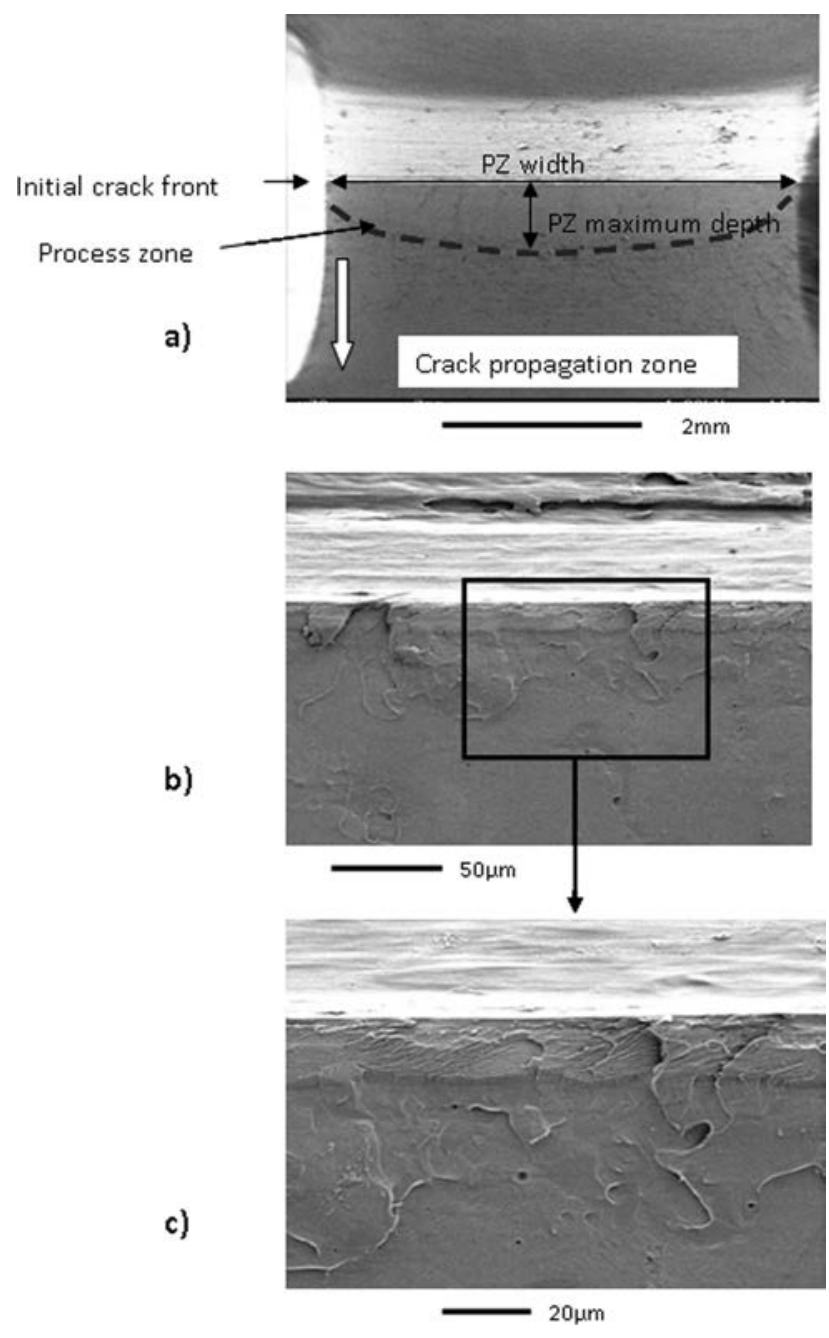

FIGURE 4 Amorphous type pattern of fracture surfaces for $0 \leq$ $\% F \leq 40$. Definitions of $P Z$ width and $P Z$ maximum depth in (a). Micrographs shown here correspond to $\% F=20$. 


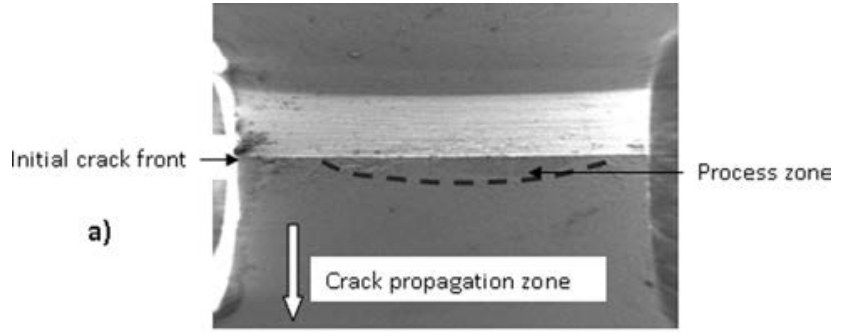

b)

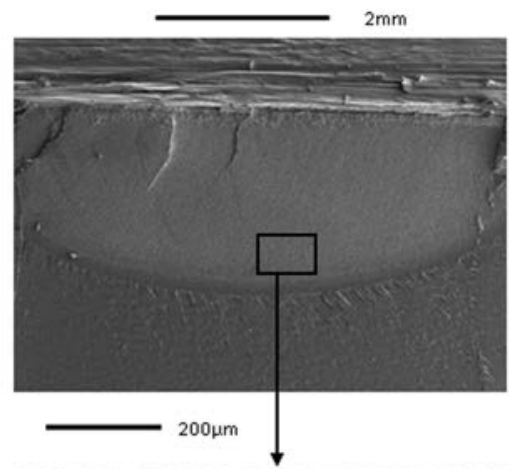

c)

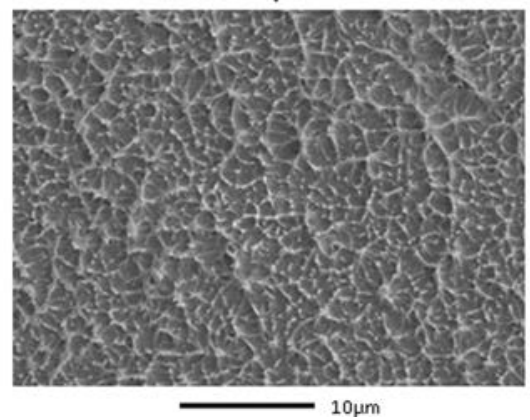

FIGURE 5 Semicrystalline type of fracture surfaces for $50 \leq \% F$ $\leq 80$. Micrographs shown here correspond to $\% F=80$.

the change in brightness. This allowed measurement of the PZ width and maximum depth, respectively (see Table 3). The fracture surface is uniformly flat. This is consistent with the amorphous character of the blend. This flat fractography will be referred to as amorphous like fracture surface. At this scale, the increase in mobility accompanying the increase in both $\% F$ and $W^{\mathrm{F}}$ a has no observable effect.

Figure 5 details analyses carried out on blends $50 \leq \% F \leq$ 80. Fracture surfaces of sample $\% F=80$ are shown here but the same observations were made with the other blends. The fracture surface is divided in two zones, the first one, just ahead of the initial crack front is a smaller part; the second one is very large and represents the brittle crack propagation. The former, the $\mathrm{PZ}$, is considered as the location of the crack initiation process where crazes develop. ${ }^{18-20}$ Again, both characteristic lengths (PZ width and PZ maximum depth) were measured and given in Table 3.

Figures 5(b, c) consist of inspections at three different scales of the PZ. Figure 5(c) clearly shows a specific pattern of regular "dimples" that are supposed to come from quasispherical voids/crazes appearing in semicrystalline polymers. ${ }^{18-20}$ Mean diameters of these dimples were estimated and gathered in Table 2 for the blends corresponding to $50 \leq \%$ $F \leq 80$.

Now, for the homopolymer PVDF $(\% F=100)$, Figure 6 summarizes the relevant observations of the fracture surface. Note that $\% F=90$ blend exhibits the same features. Figure 6 (a) shows an overview of the fracture surface. Conversely to $\% F=80$ sample, the $\mathrm{PZ}$ here shows at first [Fig. 6(b)] a surface where large extension of fibrils was observed right ahead of the blunted crack tip. Then, in Figure 6(c) typical pattern of semicrystalline fracture surface can be observed. Those are marks left by the crack front propagating within an initially crazed zone, with penny shaped crazes.,20 Typical mean diameter of these crazes measured on both $\% F$ 90-100 is about $50 \mu \mathrm{m}$. This value was added in the dimple mean diameter column in Table 3 although they are of different morphology. Figure 7 attempts to correlate the dimple mean diameter with $\% F$ and the degree of crystallinity of the blend $\chi$, respectively. A continuous increase is observed excepted for the jump between $\% F=80-90 \%$ or $\chi=$ $36-45 \%$.

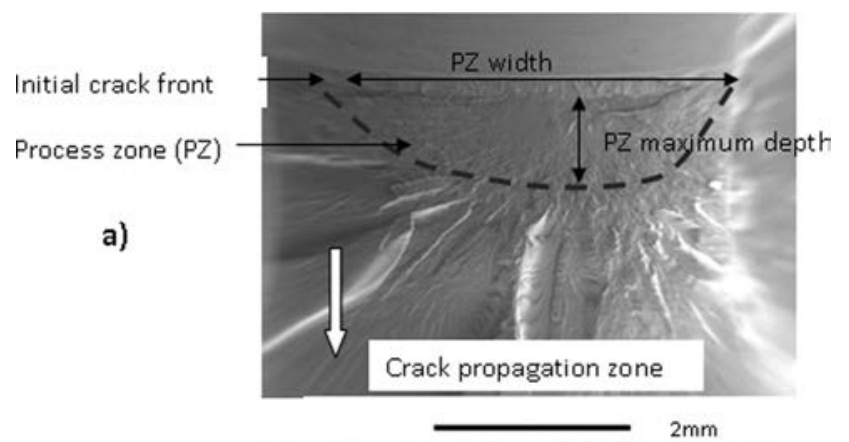

b)


FIGURE 6 Typical pattern of fracture surfaces for $90 \leq \% F \leq$ 100. Micrographs shown here correspond to $\% F=100$. 
TABLE 3 Fractography Characteristic Lengths

\begin{tabular}{llll}
\hline & $\begin{array}{l}\text { PZ Depth } \\
(\mu \mathrm{m})\end{array}$ & $\begin{array}{l}\text { PZ Width } \\
(\mu \mathrm{m})\end{array}$ & $\begin{array}{l}\text { Dimple Mean } \\
\text { Diameter }(\mu \mathrm{m})\end{array}$ \\
M & 530 & 4 & 0 \\
F/M 20:80 & 670 & 4 & 0 \\
F/M 30:70 & 440 & 4 & 0 \\
F/M 40:60 & 270 & 2 & 0 \\
F/M 50:50 & 450 & 5 & 1.2 \\
F/M 60:40 & 360 & 2 & 2.3 \\
F/M 70:30 & 440 & 3 & 5 \\
F/M 80:20 & 310 & 3 & 5 \\
F/M 90:10 & 440 & 3 & 50 \\
F & 970 & 4 & 50
\end{tabular}

For the fracture surfaces studies, three characteristic patterns were observed. The first one, corresponding to $0 \leq \% F$ $\leq 40$ showed flat fracture surface with no dimple for amorphous blends. The last two cases correspond to semicrystalline fracture surfaces with increasing value of dimple mean diameter for moderate degree of crystallinity and, at the

Dimple mean diameter $(\mu \mathrm{m})$

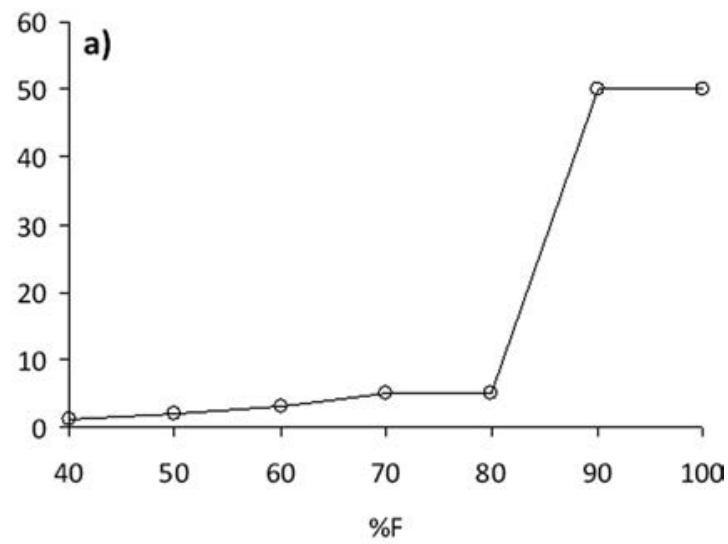

Dimple mean diameter $(\mu \mathrm{m})$

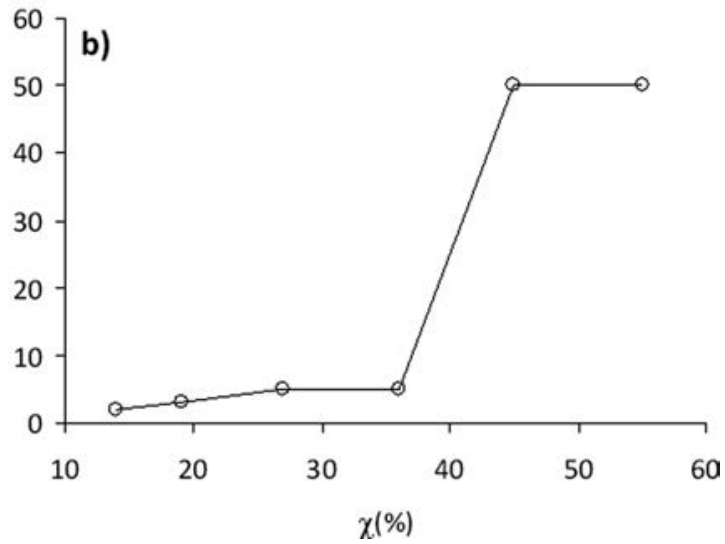

FIGURE 7 Dimple mean diameter versus PVDF contents: (a) wrt \%F; (b) wrt WFa.
PZ maximum depth $(\mu \mathrm{m}) \quad$ PZ width $(\mu \mathrm{m})$

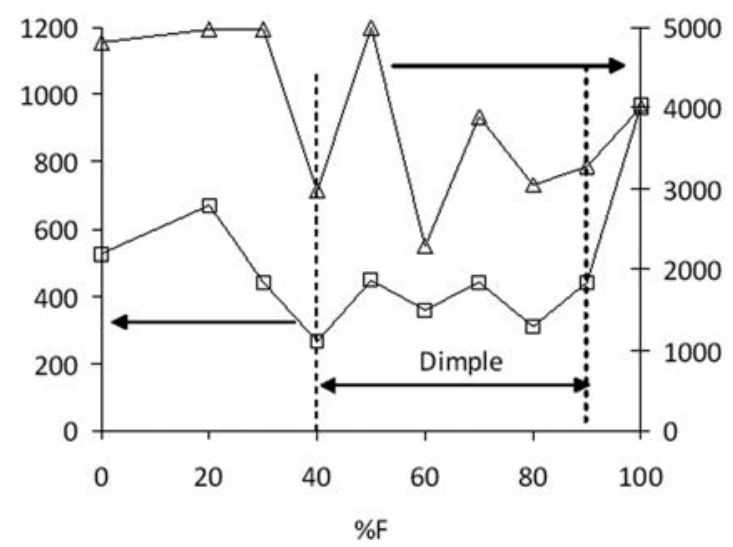

FIGURE 8 PZ depth and width as a function of PVDF contents.

extreme case $\% F(90 \leq \% F \leq 100)$, typical fracture surfaces of PVDF material appear.

To go further, Figure 8 plots $\mathrm{PZ}$ width and $\mathrm{PZ}$ maximum depth as a function of $\% F$. A large scatter is observed for both parameters. Whereas no specific trend was noticed for $\mathrm{PZ}$ width, $\mathrm{PZ}$ maximum depth seems to stabilize within the $\% F$ range for dimpled fracture surface.

\section{Correlation Between Mechanical Parameters and Fracture Surfaces Characteristics}

Although gradual increase of PVDF content was set in the blend, the above results showed that either mechanical parameters or the fracture surface analyses have to be separated according to the blend amorphous or crystalline character. The amorphous blend was characterized by, respectively, $\chi=0, \% F \leq 40$, flat fracture surface and low values of fracture energies. The semicrystalline blend $(\% F>$ $50, \chi>0$ ) exhibited dimpled fracture surfaces and transition of the fracture energy $E_{\mathrm{t}}$.

\section{Amorphous Blends}

In this first regime where $\chi=0$ the glass transition temperature $T_{\mathrm{g}}$ (Table 1 ) decreases from $\% F=0$ to $\% F=40 . E_{\mathrm{i}}$ and $E_{\mathrm{t}}$ were then plotted versus $\left(T_{\text {test }}-T_{\mathrm{g}}\right)$ as already

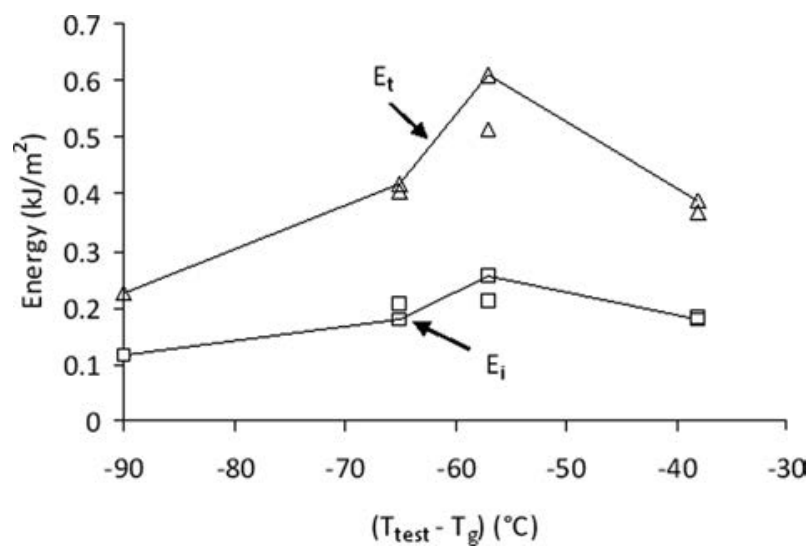

FIGURE 9 Fracture energies versus $\left(T_{\text {test }}-T_{\mathrm{g}}\right)$ for amorphous phase like fracture surface $(0 \leq \% F \leq 30) ; T_{\text {test }}=20^{\circ} \mathrm{C}$. 

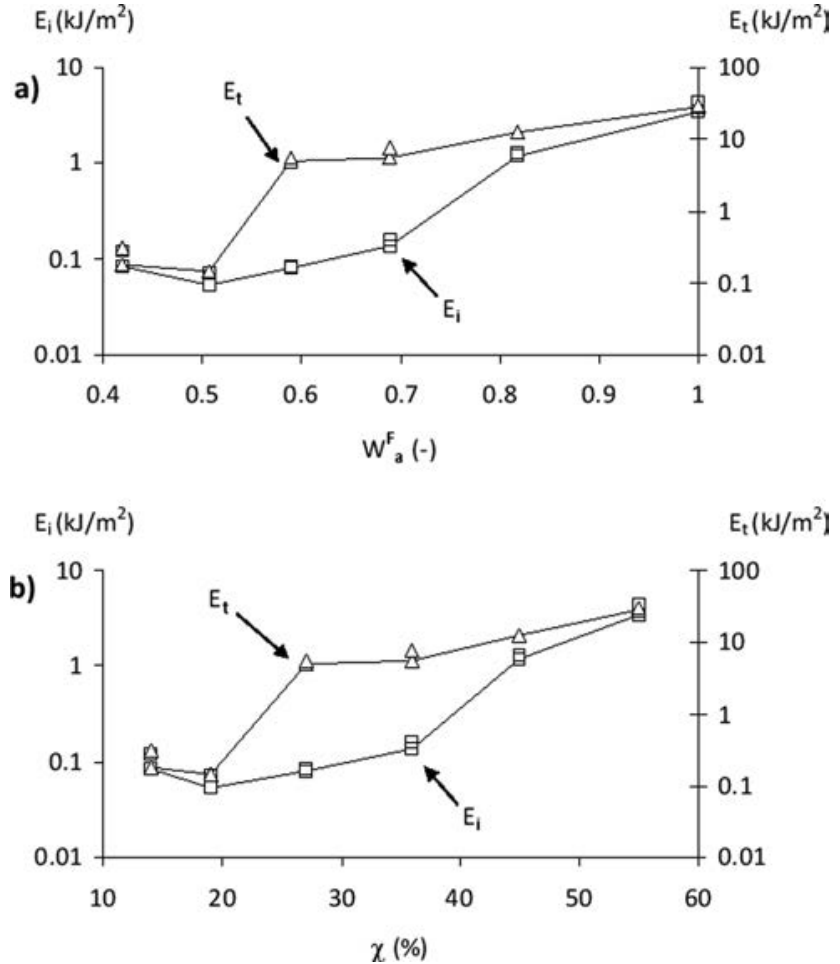

FIGURE $10 E_{\mathrm{i}}$ and $E_{\mathrm{t}}$ fracture energies for semicrystalline regime $(50 \leq \% F \leq 100)$ as a function of (a) $W^{F}$ and (b) $\chi$.

proposed for epoxy networks. ${ }^{14} T_{\text {test }}=20{ }^{\circ} \mathrm{C}$ is the test temperature. Note that $T_{\mathrm{g}}$ is quite stationary for $\% F>40$.

In Figure 9, a continuous increase in the fracture energies was observed up to $\% F=30$. The next decrease in $E_{\mathrm{i}}, E_{\mathrm{t}}$ is supposed to be due to the precursory effects of the semicrystalline character. A gain of Factor 2 in terms of toughness improvement is observed for $E_{\mathrm{t}}$ as well as for $E_{\mathrm{i}}$. This is attributed then to the change of $T_{\mathrm{g}}$ by increasing $\% F$.

\section{Semicrystalline Blends}

In this part, both $E_{\mathrm{i}}$ and $E_{\mathrm{p}}$ were plotted in Figure 10 as a function of the degree of crystallinity $\chi$ (Table 1 ) in a semilogarithmic graph in the first and second $y$-axes, respectively. In this graph, the first point where $\chi \neq 0$ corresponds to $\% F=50, W^{\mathrm{F}}{ }_{\mathrm{a}}=0.4$ whereas the last point is that of homopolymer PVDF. Both plots exhibit transitions between lower values (brittle) and upper values (ductile) for $E_{\mathrm{i}}$ and $E_{\mathrm{t}}$. Characterization of this transition depends on the selected parameters. Table 4 summarizes the values detailed here after. For the total fracture energy $\left(E_{\mathrm{t}}\right)$, the brittle to ductile transition is, respectively, estimated at $W^{\mathrm{F}}{ }_{\mathrm{a}}=0.547$ and at $\chi$ $=40.5 \%$. For the initiation fracture energy $\left(E_{\mathrm{i}}\right)$, this transition is detected at $W^{\mathrm{F}}{ }_{\mathrm{a}}=0.753$ and at $\chi=23 \%$, respectively.

The most significant gain in toughness is observed for $E_{\mathrm{t}}$ when $W^{\mathrm{F}}$ a value increases from 0.5 to 0.6 . Indeed, $E_{\mathrm{t}}$ value varies from 0.13 to $5.29 \mathrm{~kJ} / \mathrm{m}^{2}$ essentially due to large deformation during the crack propagation stage. Beyond $W^{\mathrm{F}}{ }_{\mathrm{a}}=$ $0.6, E_{\mathrm{t}}$ value gradually grows from 5.3 to $29 \mathrm{~kJ} / \mathrm{m}^{2}$.
TABLE 4 Brittle to Ductile Transition Parameters

\begin{tabular}{lll}
\hline & $E_{\mathrm{i}}$ & $E_{\mathrm{t}}$ \\
$W_{\mathrm{a}}(-)$ & 0.753 & 0.547 \\
$\chi(\%)$ & 23 & 40.5
\end{tabular}

\section{CONCLUSIONS}

Consideration of the blends of PVDF and PMMA all over the composition range proves to be a powerful tool to assess the characteristics that govern the fracture behavior of polymers. The amorphous blends (PMMA-rich materials) corresponding to $\% F \leq 40$ exhibit low values of crack initiation $E_{\mathrm{i}}$ and crack growth $E_{\mathrm{p}}$ fracture energies. Both energies have roughly the same value. Moreover, the fracture surfaces of broken specimens did not show any particular pattern, in accordance with their amorphous character. Their fracture energies are well related to the gap between the test temperature and the glass transition temperature, as already reported for other amorphous polymer series. ${ }^{14}$

In contrast, the PVDF-richer blends exhibit high degrees of crystallinity and are much tougher, especially when the PVDF content is larger than $60 \%$. The fracture surfaces show dimples characterizing semicrystalline polymers. It was observed that the mean diameter of these dimples increases with their fracture energies. Transitions from brittle to ductile fracture behavior of the blends were identified, in terms of degree of crystallinity $\chi$ or $W^{\mathrm{F}}$, depending on the selected fracture parameter. The increases in both fracture energies denote toughness improvement that can be controlled with the PVDF contents.

\section{ACKNOWLEDGMENTS}

The authors thank Julie Heurtel (Mines ParisTech) for technical support. They also thank the DYFP 2012 committee for the First Poster Prize awarded to Y. Nziakou during their meeting.

\section{REFERENCES AND NOTES}

1 Noland, J. S.; Hsu, N. N. C.; Saxon, R.; Schmitt, J. M. Adv. Chem. Ser. 1971, 99, 15-28.

2 Nishi, T.; Wang, T. T. Macromolecules 1975, 8, 909-915.

3 Patterson, G. D.; Nishi, T.; Wang, T. T. Macromolecules 1975, 9, 603-605.

4 Nishi, T.; Wang, T. T. Macromolecules 1977, 10, 421-425.

5 Léonard, C.; Halary, J. L.; Monnerie, L.; Micheron, F. Polym. Bull. 1984, 11, 195-202.

6 Faria, O.; Moreira, R. L. Polymer 1999, 40, 4465-4471.

7 Jarray, J. Ph.D. Thesis, University Tunis El Manar, Tunisia, February 12, 2005.

8 Jarray, J.; Ben Cheikh Larbi, F.; Vanhulle, F.; Dubault, A.; Halary, J. L. Macromol. Symp. 2003, 198, 103-116.

9 Halary, J. L.; Jarray, J.; Fatnassi, M.; Ben Cheikh Larbi, F. J. Eng. Mater. Technol. 2012, 134, 010910.

10 Landes, J. D.; Begley, J.A. Fracture Analysis, STP 560; American Society for Testing Analysis: Philadelphia, 1974; pp 170-186. 11 Folch, L.; Burdekin, F. Eng. Fract. Mech. 1999, 63, 57-80. 
12 Rossol, A.; Berdin, C.; Prioul, C. Int. J. Fract. 2002, 115 205-226.

13 Tanguy, B.; Bouchet, C.; Bugat, S.; Besson, J. Eng. Fract. Mech. 2006, 73, 191-206.

14 Laiarinandrasana, L.; Fu, Y.; Halary, J. L. J. Appl. Polym. Sci. 2012, 123, 3437-3447.

15 Challier, M.; Besson, J.; Laiarinandrasana, L.; Piques, R. Eng. Fract. Mech. 2006, 73, 79-90.

16 Laiarinandrasana, L.; Besson, J.; Lafarge, M.; Hochstetter, G. Int. J. Plast. 2009, 25, 1301-1324.
17 Laiarinandrasana, L.; Hochstetter, G.; Lafarge, M. In Proceedings of the 16th European Conference of Fracture, Alexandroupolis, July 3-7, 2006; Greece.

18 Kausch, H. H. Polymer Fracture, 2nd ed.; Springer Verlag: Berlin, Heidelberg, 1987.

19 Grein, C.; Plummer, C. J. G.; Kausch, H. H.; Germain, Y.; Béguelin, Ph. Polymer 2002, 43, 3279-3293.

20 Plummer, C. J. G.; Goldberg, A.; Ghanem, A. Polymer 2001, 42, 9551-9564. 